\title{
FAMILY PLANNING - A CARE FOR THE FUTURE
}

\author{
E. Brandiyska
}

Third year student Midwife, Affiliation of Haskovo, Trakia University of Stara Zagora,

\begin{abstract}
Bulgarian Family Planning and Sexual Health Association (BFPA) is a non-governmental organization, officially accredited member of the International Planned Parenthood Federation.

Introduction: BFPA has initiated and completed a lot of national campaigns independently or in a partnership, such as: increase young people awareness towards prevention measures of HIV/AIDS and sexually transmitted infections, promotion of health ideas, improve access to health care services focused on marginalized and socially deprived groups etc.

Aim: The aim of this work is to conduct an inquiry if people are informed about family planning and if they need any support by the specialists working there.

Materials and methods: The study has been made by an own direct anonymous inquiry. The applied methods are documental, sociological and statistical.

Results: The results from the sociological study show that the majority of the population in Haskovo and Pazardzhik region has no idea about the purposes of the organization and does not know in which situations could ask for its help and what kind of qualified medical care could receive.

Conclusion: The majority of the inquired people does not know anything about the family planning and does not know about the existence of an organization which is oriented towards solving the problems with sexual and reproductive health.
\end{abstract}

Key words: association, family planning, sexual health, reproductive health

\section{INTRODUCTION}

Bulgarian Family Planning and Sexual Health Association (BFPA) is a non-governmental organization, officially accredited member of the International Planned Parenthood Federation.

It has been doing different kinds of work with various target groups:

- Adolescents at schools

- Young people in the institutions - sociopedagogical boarding schools, foster homes

- Young people with special educational needs

- Students

- Women and men who have restricted access to service and information in the field of health

- Disadvantaged groups - Gypsies, socially deprived people, people carrying HIV virus in their blood

Since the organization has been founded it has organized over than 302500 gynecological and contraceptive consultations. It has conducted over than 28000 consultations and tests about HIV virus, HBV virus, HCV virus, Chlamydia, syphilis and other sexually transmitted infections.

The organization creates educational materials for the adolescents with special educational needs in the field of sexual and reproductive health, introduces the idea of mobile services in the inaccessible and remote areas in the sphere of the reproductive health, and in cooperation with different partners approves the role of the health mediator as very important in the work with vulnerable groups. The term sexual health is used to illustrate the lack of any illness or disability connected to the sexual behaviour. The term is defined as "positive integration of the physical, emotional, intellectual and social aspects of the sexuality." World Health Organization defines the reproductive health as a condition of total physical, mental and social wealth, and not only the lack of disease in any aspect connected to the reproductive system and its functions and processes. /5/

In 2007 BFPA took a new direction into its activity aiming the prevention of the sexual and the reproductive health. The association 
organizes events connected to the human trafficking especially trafficking of women for sexual exploitation. The project is taking place in small town or villages where the level of unemployment is quite high and for that reason a great number of women are provoked to look for a job abroad. The BRPA team which works on the program organizes monthly examinations which include consultations and examinations in the field of obstetrics and gynecology, venereology, sexology and psychotherapy. One of the main goals of the organization is to assist in providing safe conditions for abortion by request. /2/

The specialists in BFPA are trying to find a solution of different problems among the married couples. The difficulties in married life which require special medial help can start in different ways. In a normal, stable and long marriage the spouses should adapt themselves to each other in social, ethic, financial and sexual aspect. The disharmony in any of these aspect leads to a serious problem in sexual plan. The effective consultation requires a deep understanding of the partners' relationships in any of these aspects. /1/ Men and women have the right to be informed and to have access to safe, effective and acceptable methods of family planning at their will as well as other methods chosen by themselves which are not illegal for regulating the reproduction. They have the right to get adequate health services which will allow women to have a safe pregnancy and birth and for the couples will assure the best opportunity to have a healthy baby. /5/

THE AIM of this work is to conduct an inquiry if people are informed about family planning, if they received some information about the existence of an Association which occupation is to take care of problems connected with the sexual and reproductive health (BFPA) and if people need any specialised medical help when dealing with different problems. The inquiry aims to show if people know that various medical specialists (obstetricians, sexologists, venereologists, psychologists) work in this organization that could help in solving people's problems through consultations and some advice.

\section{MATERIALS AND METHODS}

The study has been made by an own direct anonymous inquiry. The respondent men and women are chosen at random from different age groups in the towns of Haskovo and Pazardzhik as well as a group of students from Trakia University Affiliation of Haskovo. The study has been conducted from November to March. 200 people have been taken part in.

The applied methods are documental, sociological and statistical.

\section{RESULTS AND DISCUSSIONS}

The respondents chosen at random get into age group 19-25 in towns of Haskovo and Pazardzhik. (Figure 1)
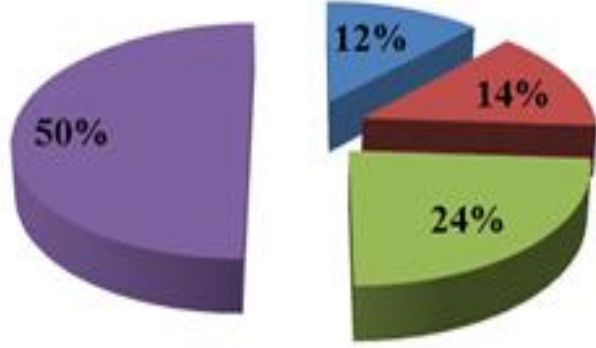

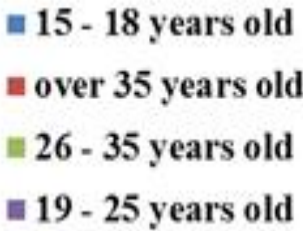

Figure 1. Age groups
These are young people who are going to think about family and children and the necessity of family planning is quite big. They need to be supported in difficult moments and to be oriented about the prevention of unwanted pregnancy and sexually transmitted infections. It will be very useful for girls between 15 and 18 to have information about the normal menstrual cycle (ovarian, endometrial, cervical cycle). It will also be useful for women over 35 to have information about the opportunities for screening of the reproductive health - case history taking, physical examination, breast and cervical cancer screening, gynecological examination. Later it is a good idea to pay attention on the menopause conditions since they may have some effect on the physical and psychical women's health. The majority of the respondents give a positive answer to the question if they have a regular sexual life (58\%), (Figure 2)

They need to be informed about the prevention of unwanted pregnancy, contraception, abortions and sexually transmitted infections. 


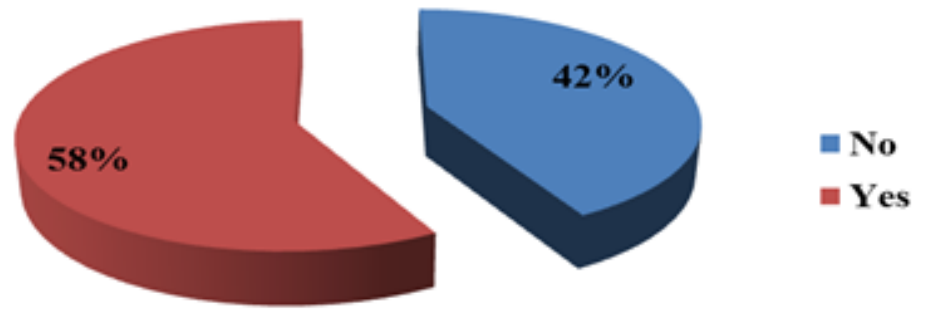

Figure 2. Sexual life

The consultation in the BFPA centers before the abortion procedure aims to give women some instructions about what will happen before, during and after the procedure; the safety of the procedure; the side effects and the eventual possible complications. Lately the association organizes different campaigns focused on rising people awareness about HIV/AIDS. Different ways are used to get the information to the target groups as well as organizing lectures at schools, promoting events in discos and clubs, disseminating of leaflets and brochures.

The study shows that questions associated with the sexual growth and life are taboo subject for the majority of families. Children gather information from non-trusted sites and there are occasional campaigns on December the $1^{\text {st }}$ - World AIDS Day. In 2001 BFPA realized one of the first national campaigns to get over the barriers in using condoms by the slogan: "Do you look for an apology? Don't make excuses! Use condoms!"

Two third of the respondents do not know about the existence of a Family Planning Association which is a non-governmental organization. (Figure 3) People who know that are students form specialty Health Care.

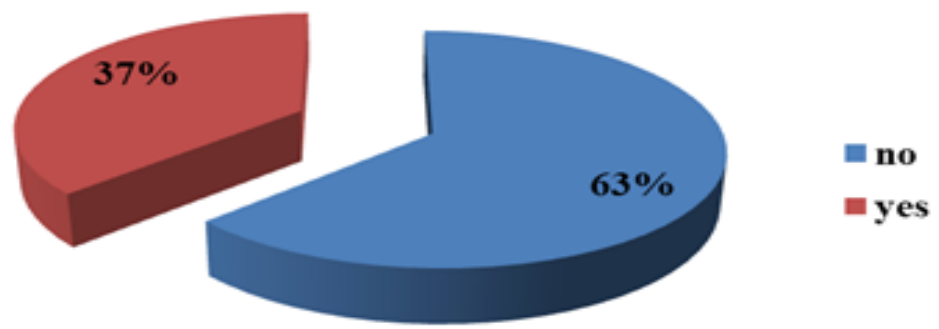

Figure 3. BFPA in Bulgaria

BFPA has initiated and completed a lot of national campaigns independently or in a partnership, such as: increase young people awareness towards prevention measures of HIV/AIDS and sexually transmitted infections, promotion of health ideas, improve access to health care services focused on marginalized and socially deprived groups etc.

The respondents have been asked what they know about the family panning. The majority of them have answered that they have heard about it but they are not very well informed.

(Figure 4)

$$
\text { myes }
$$

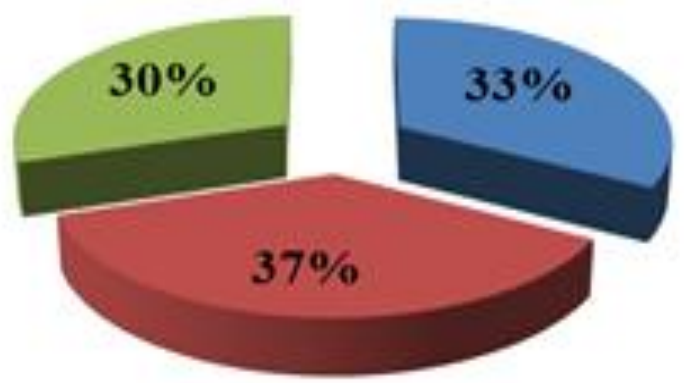

\section{E've heard about it but $I$ do not have much information on the topic}

Figure 4. Family planning

The information that people get comes mostly from the Internet or from their GP. Only students who study Health Care get information from the scientific literature and they are ready to organize the so called informational and educational days at schools. 
Thanks to BFPA for the first time in our country is initiated the interactive method in the field of the health education as well as the new approach "peer education" which can be applied among the growing up and the vulnerable minorities.

Examples of advocacy initiatives of BFPA are innumerous - including health and sexual education in the school programs, affirmation the position of the gypsy health mediator, support in realizing the national strategy to combat HIV virus, active assistance from the non-governmental sector in the strategies for world development of the EU.

More than the half of the respondents think that they need more informative campaign about the Family Planning Centers. (Figure 5)

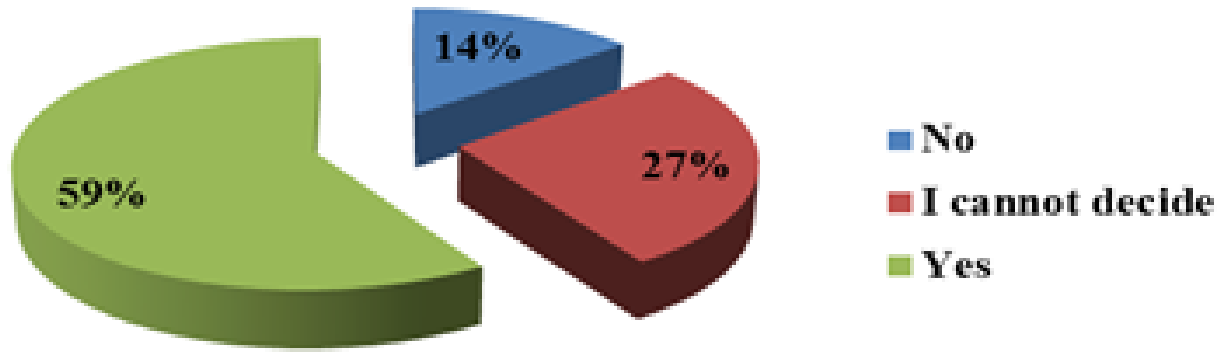

Figure 5. Information campaigns

Bulgarian Family Planning and Sexual Health Association realizes activities in the field of advocacy, promotion and defense of the sexual and reproductive health as an integral part of the human rights.

On the question: "Would you ask for help a specialist working in a consulting room for family planning if you have problems bringing up your children or if you need some advice about their sexual and reproductive health?" 42 $\%$ answer that they will do it, $14 \%$ answer that they do not need such help. The rest $44 \%$ are not sure if they will look for such help which means they are skeptical because they are not well informed about the help opportunities of BFPA. (Figure 6)

In the Bulgarian Family Planning and Sexual Health Association work different specialists in the field of medicine - obstetricians, gynecologists, venereologists, sexologists, psychologists who can help people dealing with their problems through realizing consultations and giving some useful advice. Thanks to them a thousands of anonymous examinations and tests for sexual transmitted diseases are conducted in the medical centers.

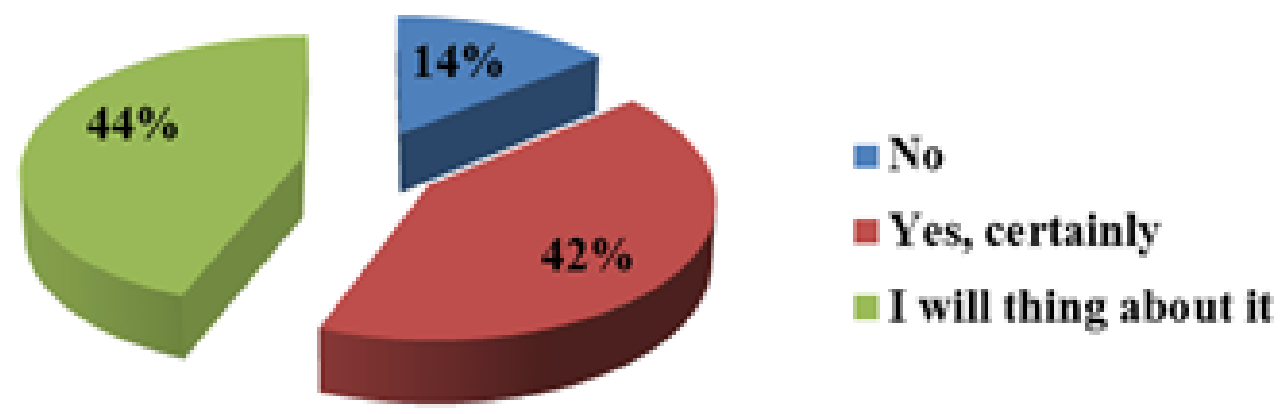

Figure 6. Consultation in BFPA

The inquiry shows that the majority of the respondents would ask for advice a Family Planning Center $/ 56 \% /, 24 \%$ are sure they do not need any advice and the rest $20 \%$ will ask for help after increasing the trust in the nongovernmental organizations. (Figure 7) The majority of people who have received help from the specialists working in BFPA would recommend to their close friends to look for some advice in the centers for family planning if they need it.

In conclusion it is obvious that the population and the respondents need awareness campaigns and understandable information about the family planning. 

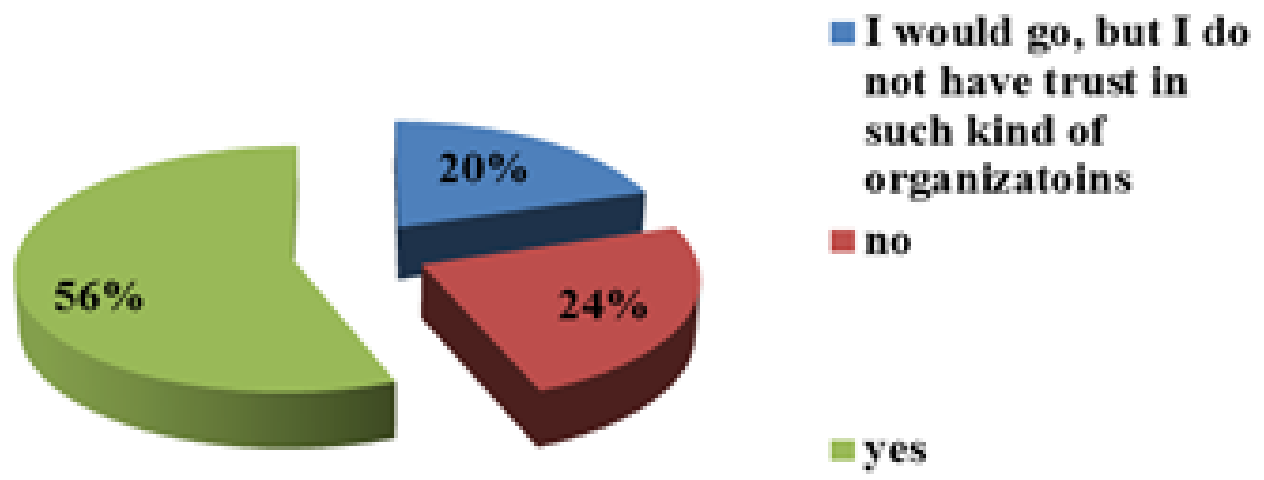

Figure 7. Trust in BFPA

\section{CONCLUSION}

- People do not know about the existence of BFPA

- The majority of the respondents do not know that specialists from different fields work in the consulting rooms for family planning and these specialists could help them in overcoming the different moment in their life. In these consulting rooms people can receive some support and qualified medical help.

- People agree to look for qualified medical help from non-governmental organization like BFPA if they have a problem

- People from towns of Haskovo and Pazardzhik need such family planning centers which will have a positive, health and social impact.

\section{REFERENCES}

1. Prof. I. Karagyozov, d.m.n., Obstetrics, Medicine and physical education, Sofia2005

2. http://www.safesex.bg

3. Medical guidelines for sexual and reproductive health services, Third edition, 2004

4. Anika Pen,Advocacy guidelines for reproductive health of the young people in Eastern Europe and Central Asia, 2004

5. Associate prof. Diana Dimitrova, d. ps., http://www.varnaparents.com/akusherstvo/s emeino_planirane.html 